BMJ Open Ophthalmology

\title{
Microbial keratitis and the selection of topical antimicrobials
}

\section{Stephen Kaye}

Microbial keratitis is a major cause of corneal opacity and loss of vision worldwide, and topical antimicrobial therapy is a critical component in its management. The study by Austin et $a l^{1}$ found that there are regional variations in practice patterns influenced by concern over availability and toxicity versus broad-spectrum coverage and resistance. Respondents in the USA were more likely to treat with fortified antibiotics than their international peers. ${ }^{1}$

This raises some important points and questions in the treatment of suspected bacterial keratitis.

Why do some clinicians opt for monotherapy and others fortified antimicrobials? What is understood by combination therapy? What are the treatment considerations when the microbiological report says susceptible or resistant?

The clinical outcome in microbial keratitis is dependent on host factors, the virulence of the infecting bacteria and the minimum inhibitory concentration (MIC) of the antimicrobial against the respective bacteria. ${ }^{2-4}$ The MIC is used to determine susceptibility criteria in order to choose an appropriate antimicrobial for treatment. ${ }^{5-7}$ Although there is a relationship between clinical outcome and the MIC of antimicrobials in microbial keratitis, the actual MICs of the available antimicrobials against the respective isolate are seldom provided to the clinician. In addition, resistance and susceptibility are usually based on systemic breakpoint criteria rather than ophthalmic breakpoints. ${ }^{4}$ That is, the breakpoints that are used to determine resistance and susceptibility are based on the anticipated response of the bacteria against concentrations of the antimicrobial that can be achieved in serum. Clearly, the antimicrobial concentrations achieved in the cornea and aqueous humour following topical administration differ from that achieved in the serum following systemic administration. The corneal penetration and effectiveness of a topical antimicrobial agent is dependent on the physicochemical properties of the antimicrobial and structure of the cornea. ${ }^{8-11}$ In addition, the $\mathrm{pH}$ and protein binding of the local environment and interaction with other agents not only differ from systemic conditions but also differ in the non-inflamed to the inflamed eye added to mixing with the tear film. ${ }^{12-14}$ Furthermore, the concentration of an antimicrobial does not necessarily equate to the activity and bioavailability of the drug. ${ }^{15}$ The biological activity of an antimicrobial in the cornea is usually much lower than the chemical concentration and may be less than $10 \%$ of the instilled amount. ${ }^{12-}$ ${ }^{15}$ For these reasons, the setting and use of ophthalmic breakpoints is very limited.

The comparative antimicrobial activity of antimicrobials against a particular bacterial species, however, is an important guide to selecting treatment. The fluoroquinolones are effective agents used to treat microbial keratitis. ${ }^{16}$ It is, however, important to be selective in choosing a particular fluoroquinolone for a particular bacteria. For example, for the equivalent concentration, ciprofloxacin has a better inhibitory effect against Pseudomonas aeruginosa than moxifloxacin or levofloxacin. ${ }^{7}$ The effectiveness of the fluoroquinolones against bacteria such as streptococcus and strains of staphylococcus may be limited. Although the newer generation fluoroquinolones have enhanced activity against Gram-positive bacteria, these agents are not a panacea for the treatment of microbial keratitis, particularly with the emergence of resistant strains of staphylococci, streptococci and Enterobacteriaceae. ${ }^{17-21}$ As such, there is a need to consider other antimicrobials for topical administration, such as meropenem, or combination therapy. ${ }^{22-24}$

As opposed to single therapy, an antimicrobial combination offers a broader spectrum of activity and may reduce selective pressures. Either knowingly or unknowingly, ophthalmologists use combination therapy either simultaneously or 
sequentially, for example, a fluoroquinolone followed by chloramphenicol. This leads to an effect of indifference, addition, synergism or antagonism. Although the use of combination therapy may increase the spectrum, the potential benefit is to increase the antimicrobial effect of the respective combination, that is, an additive or preferably a synergistic effect. For example, the combination of penicillin and gentamicin in the treatment of enterococcal endocarditis produces a synergistic effect, ${ }^{25}$ whereas conversely, the combination of chloramphenicol and penicillin in the treatment of pneumococcal meningitis is antagonistic. ${ }^{26}$ It is important, therefore, to select a combination which is either additive or synergistic and to avoid a combination which is antagonistic. For keratitis isolates, it has been shown in vitro that the combination of meropenem and ciprofloxacin was synergistic in $20 \%-25 \%$ and either additive or synergistic in 55\%-60\% of both Staphylococcus aureus and $P$. aeruginosa keratitis isolates. ${ }^{22}$ Against $S$. aureus, the combinations of teicoplanin with meropenem, ciprofloxacin or moxifloxacin had an additive or synergistic effect in more than $50 \%$ of $S$. aureus keratitis isolates. ${ }^{22}$

Although there has been debate, an overriding issue in improving the treatment of suspected microbial keratitis is the need to sample a corneal ulcer and to try and isolate the microorganism. ${ }^{27}{ }^{28}$ Larger corneal ulcers usually start off as smaller ulcers and the need for a simple and readily available method for use in all cases to identify and isolate the causative microorganism(s) would be a significant advantage. ${ }^{29} 30$ This together with adjunctive antibacterial therapy against the bacterial toxins and virulence factors would be significant forward steps in improving outcomes in microbial keratitis.

There is a clear need to establish ophthalmic breakpoints to aid the ophthalmologist in deciding on the appropriate antimicrobial treatment. These would then form the basis for author's suggestion of a 'welldesigned clinical trial on the treatment of bacterial ulcers to help clinicians initiate the best treatment and ultimately reduce morbidity. ${ }^{1}$

\section{Competing interests None declared.}

Provenance and peer review Commissioned; internally peer reviewed.

Open Access This is an Open Access article distributed in accordance with the Creative Commons Attribution Non Commercial (CC BY-NC 4.0) license, which permits others to distribute, remix, adapt, build upon this work noncommercially, and license their derivative works on different terms, provided the original work is properly cited and the use is non-commercial. See: http:// creativecommons.org/licenses/by-nc/4.0/

(c) Article author(s) (or their employer(s) unless otherwise stated in the text of the article) 2017. All rights reserved. No commercial use is permitted unless otherwise expressly granted.

\section{REFERENCES}

1. Austin A, Schallhorn J, Geske M, et al. Empiric treatment of bacterial keratitis: an international survey of corneal specialists. $B M J$ Ophthalmol.

2. Wilhelmus KR, Abshire RL, Schlech BA. Influence of fluoroquinolone susceptibility on the therapeutic response of fluoroquinolone-treated bacterial keratitis. Arch Ophthalmol 2003;121:1229-33.

3. Chen A, Prajna L, Srinivasan M, et al. Does in vitro susceptibility predict clinical outcome in bacterial keratitis? Am J Ophthalmol 2008; 145:409-12.

4. Kaye S, Tuft S, Neal T, et al. Bacterial susceptibility to topical antimicrobials and clinical outcome in bacterial keratitis. Invest Ophthalmol Vis Sci 2010;51:362-8.

5. Greenwood D. In vitro veritas? Antimicrobial susceptibility tests and their clinical relevance. J Infect Dis 1981;144:380-5.

6. Lorian V, Burns L. Predictive value of susceptibility tests for the outcome of antibacterial therapy. J Antimicrob Chemother 1990;25:175-81.

7. Sueke H, Kaye S, Neal T, et al. Minimum inhibitory concentrations of standard and novel antimicrobials for isolates from bacterial keratitis. Invest Ophthalmol Vis Sci 2010;51:2519-24.

8. Burstein NL, Anderson JA. Corneal penetration and ocular bioavailability of drugs. J Ocul Pharmacol 1985;1:309-26.

9. Frangie JP. Clinical pharmacokinetics of various topical ophthalmic delivery systems. Clin Pharmacokinet 1995;29:130-8.

10. Mishina S. Clinical pharmacokinetics of the eye. Invest Ophthalmol Vis Sci 1981;21:504-41.

11. Shell JW. Pharmacokinetics of topically applied ophthalmic drugs. Surv Ophthalmol 1982;26:207-18.

12. Benson H. Permeability of the cornea to topically applied drugs. Arch Ophthalmol 1974;91:313-27.

13. Bouchard CS, King KK, Holmes JM. The kinetics of anterior chamber ofloxacin penetration. Cornea 1996;15:72-5.

14. Cahane M, Ben Simon GJ, Barequet IS, et al. Human corneal stromal tissue concentration after consecutive doses of topically applied 3.3\% vancomycin. Br J Ophthalmo/ 2004;88:22-4.

15. Kaye SB, Neal T, Nicholson S, et al. Concentration and bioavailability of ciprofloxacin and teicoplanin in the cornea. Invest Ophthalmol Vis Sci 2009;50:3176.

16. Smith A, Pennefather PM, Kaye SB, et al. Fluoroquinolones: place in ocular therapy. Drugs 2001;61:747-61.

17. Park SH, Lim JA, Choi JS, et al. The resistance patterns of normal ocular bacterial flora to 4 fluoroquinolone antibiotics. Cornea 2009;28:68-72.

18. Miller D, Flynn PM, Scott IU, Alfonso EC, et al. In vitro fluoroquinolone resistance in staphylococcal endophthalmitis isolates. Arch Ophthalmol 2006;124:479-83.

19. Moshirfar M, Mirzaian G, Feiz V, et al. Fourth-generation fluoroquinolone-resistant bacterial keratitis after refractive surgery. $J$ Cataract Refract Surg 2006;32:515-8.

20. Rau G, Seedor JA, Shah MK, et al. Incidence and clinical characteristics of enterococcus keratitis. Cornea 2008;27:895-9.

21. Feiz V, Redline DE. Infectious scleritis after pars plana vitrectomy because of methicillin-resistant Staphylococcus aureus resistant to fourth-generation fluoroquinolones. Cornea 2007;26:238-40.

22. Sueke H, Kaye S, Wilkinson MC, et al. Pharmacokinetics of meropenem for use in bacterial keratitis. Invest Ophthalmol Vis Sci 2015;56:5731-8.

23. Sueke $\mathrm{H}$, Kaye SB, Neal T, et al. An in vitro investigation of synergy or antagonism between antimicrobial combinations against isolates from bacterial keratitis. Invest Ophthalmo/ Vis Sci 2010;51:4151-5.

24. Guzek JP. Problems with monotherapy for bacterial keratitis. Invest Ophthalmol Vis Sci 2010;51:6902.

25. Moellering RC, Wennersten C, Weinberg AN. Synergy of penicillin and gentamicin against Enterococci. $J$ Infect Dis 1971;124:S207-S213.

26. Friedland IR, Klugman KP. Failure of chloramphenicol therapy in penicillin-resistant pneumococcal meningitis. Lancet 1992;339:405-8.

27. McDonnell PJ. Empirical or culture-guided therapy for microbial keratitis? A plea for data. Arch Ophthalmol 1996;114:84-7.

28. McLeod SD, Kolahdouz-Isfahani A, Rostamian K, et al. The role of smears, cultures, and antibiotic sensitivity testing in the management of suspected infectious keratitis. Ophthalmology 1996;103:23-8.

29. Kaye SB, Rao PG, Smith G, et al. Simplifying collection of corneal specimens in cases of suspected bacterial keratitis. J Clin Microbiol 2003:41:3192-7.

30. Kaye S, Sueke H, Romano V, et al. Impression membrane for the diagnosis of microbial keratitis. Br J Ophthalmol 2016;100:607-10. 